\title{
THE NATURE OF FIBROSITIS
}

\section{I. A STUDY OF THE CAUSATION OF THE MYALgIC LESION (RHEUMATIC, TRAUMATIC, INFECTIVE)}

BY

\author{
MICHAEL KELLY
}

Perth, Western Australia

A theory of fibrositis advanced in a previous paper (1945) suggested that the disorder commonly represents the widely spread reflex effects of a myalgic lesion. These reflex effects are: (1) widespread pain, (2) deep hyperalgesia, (3) oedema of the involved tissues, and (4) stiffness or wasting of muscles. The pain often spreads in patterns which show a tendency to remain constant for any one region of the body; and the myalgic lesion itself shows a predilection for certain localities, mostly in the region of the musculo-tendinous junctions. It was suggested also that the simple mechanism of an axon-reflex was sufficient to explain the radiation of pain and hyperalgesia to a medium distance from the lesion. Where a leap of several segments occurred, however, it was suggested that one or more relays must take place in the spinal cord. In this essay an attempt will be made to describe the patterns of pain found in several regions of the body; and cases will be quoted which suggest that, no matter what the original cause, the well-established fibrositic syndrome presents remarkably constant features.

\section{The Myalgic Lesion and Local Analgesia}

It is not intended to imply that the pain-patterns are ruled by anything like an inflexible law, for a myalgic lesion, typical in its general features and in its response to local analgesia, may be found wherever muscular tissues are found. When sharply localized lesions are found in pure fibrous tissue, as in the capsules of joints or the attachments of tendons, their behaviour is different, and they are not usually amenable to treatment by local infiltration. Local analgesia has proved a valuable weapon, both as a therapeutic measure and as a means of investigation. In the majority of cases the infiltration of the lesion was followed by the immediate disappearance of the widespread pain, tenderness, and muscular stiffness, and in 30 to $40 \%$ of cases this relief was lasting. For the purpose of this essay, those cases only will be quoted in which lasting cure resulted immediately from a single injection, and in which the lesion was "typical" in its location. It should be borne in mind, however, that the writer does not wish to imply either that the majority of cases can be cured in this fashion, or that in more than 50 to $60 \%$ of cases is the lesion " typical" in its situation.

Pain in any region can frequently be proven due

TABLE

\begin{tabular}{|c|c|}
\hline Type of Pain & Location of Lesion \\
\hline $\begin{array}{l}\text { 1. Headache, occipital } \\
\text { or frontal }\end{array}$ & $\begin{array}{l}\text { Neck muscles below superior } \\
\text { nuchal line, near apex of } \\
\text { angle made by sterno-mas- } \\
\text { toid with trapezius (Figs. } 2 \\
\text { and } 3 \text { ). }\end{array}$ \\
\hline $\begin{array}{l}\text { 2. Shoulder pain, radi- } \\
\text { ating down to in- } \\
\text { setion of deltoid }\end{array}$ & $\begin{array}{l}\text { Middle of supraspinous fossa } \\
\text { (Figs. } 4 \text { and 5) }\end{array}$ \\
\hline $\begin{array}{l}\text { 3. Pain in forearm and } \\
\text { hand }\end{array}$ & $\begin{array}{l}\text { Extensor mass at level of neck } \\
\text { of radius (Figs. 7, 8 and } \\
\text { 12) }\end{array}$ \\
\hline 4. Pleurodynia & $\begin{array}{l}\text { Intercostal muscles, usually } \\
\text { near the anterior axillary } \\
\text { line (Fig. 9) }\end{array}$ \\
\hline 5. Abdominal pain & $\begin{array}{l}\text { Edge of erector spinae or edge } \\
\text { of rectus abdominis (Fig. 10) }\end{array}$ \\
\hline 6. Low backache & $\begin{array}{l}\text { Edge of erector spinae muscle, } \\
\text { or gluteus maximus in sacro- } \\
\text { iliac region (Fig. 11) }\end{array}$ \\
\hline 7. "Sciatic" pain & $\begin{array}{l}\text { Gluteus maximus about centre, } \\
\text { or hamstrings near musculo- } \\
\text { tendinous junction }\end{array}$ \\
\hline 8. Painful knee & $\begin{array}{l}\text { Deep tissues in region of } \\
\text { adductor tubercle }\end{array}$ \\
\hline 9. Painful calf & $\begin{array}{l}\text { Whether traumatic or not } \\
\text { singularly resistant to per- } \\
\text { manent cure by local infiltra- } \\
\text { tion. Temporary abatement } \\
\text { frequently obtained by treat- } \\
\text { ing lesion behind inner con- } \\
\text { dyle of tibia }\end{array}$ \\
\hline 10. Fibrositis of sole & $\begin{array}{l}\text { Apex of longitudinal arch near } \\
\text { inner border (Local an- } \\
\text { algesia almost invariably } \\
\text { unsuccessful) }\end{array}$ \\
\hline 1. $\mathrm{Cr}$ & Abductor pollicis near centre \\
\hline
\end{tabular}


to a typical muscular lesion, as in the Table and in Fig. 1. The writer has met with much scepticism regarding the value of the method and the results obtained; this has been the experience also of other workers in this field (Travell, 1945; Gorrell, 1944). The examiner, however, should be prepared to devote unlimited time to his search for the muscular lesion; and it is only after a good deal of experience that a reliable idea can be gained of the normal and

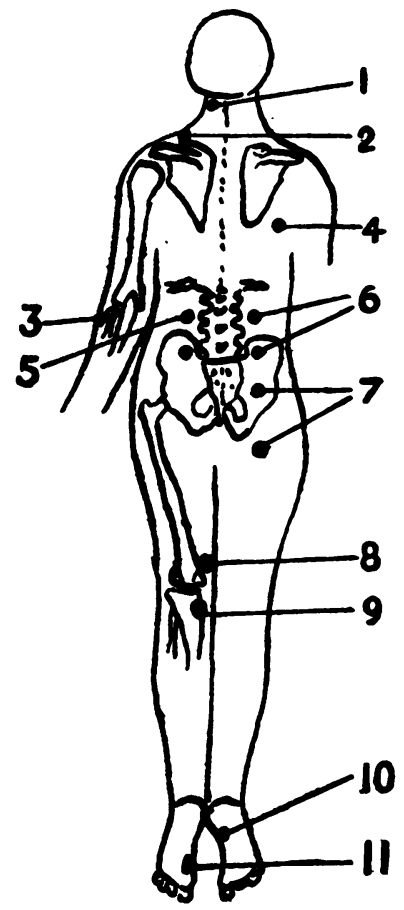

FIG. 1.-Majority of common sites demonstrated ; numbered as in the Table.

abnormal sensitivity of muscles to deep palpation. The method of infiltration, too, has not been well served by its over-enthusiastic protagonists who too often claim dramatic successes in the vast majority of cases.

\section{Varieties of Somatic Pain}

It is customary for writers upon fibrositis to divide their cases into two classes, depending upon causation: (1) primary, arising apparently de novo; (2) secondary, following injury or occurring with such diseases as rheumatoid arthritis and rheumatic fever. In addition, many painful states occur which are not usually classified as fibrositis, though the established clinical picture does not differ from that of fibrositis in the same situation. In these may be included: (a) headache from various causes, as some cases following head injuries or meningitis; (b) pleurodynia following pneumonia or bronchitis or other diseases of the lung; (c) abdominal pain following operations on the abdomen, or inflammatory diseases such as hepatitis and dysentry; (d) persistent backache after renal colic or infection of the kidney; (e) "sciatica" due to supposed lesions of the intervertebral disc. It was only after a considerable time that the writer came to realize that, no matter what the original cause of a persisting somatic pain, the pain tends at length to assume the qualities and the distribution of fibrositis in that region; and in many such cases treatment of a muscular lesion is rewarded by complete and lasting relief. A few illustrative examples follow.

\section{HEADACHES OF SOMATIC ORIGIN}

Thirty-five cases have been studied in which significant results have followed the use of local anaesthesia to deep cervical lesions; this number represents only about $25 \%$ of the cases under observation. In 20 of the 35 cases the lesion was situated in the region indicated in the Table and in Figs. 1 and 2: for brevity's sake the writer refers to this as the "lateral nuchal spot" (Kelly, 1942b).

CASE 1

Headache, probably "rheumatic" in origin.-L/Sgt. A.B. complained of headaches for a year, which had become worse recently, and for a week they had been unbearable. The Regimental Medical Officer feared that he had an intracranial lesion. A continuous pain was felt in the occipital region on both sides, with a feeling of tansion on the vertex. Complete examination revealed no abnormality except slight tenderness to deep pressure in both lateral nuchal regions. After resting in bed for 4 days the headache was no better; on examination the left nuchal region was tender, but the right was not (Fig. 2). Two cubic centimetres, $0.5 \%$ procaine, were injected into the left nuchal spot, and two days later the patient left hospital completely free trom headache and feeling well. Three months later he reported that the cure had been complete.

CASE 2

Headache following fracture of the skull.-Able-Seaman $X$. was knocked unconscious and sustained a linear fracture of the left parietal bone. For a month afterwards he complained of a continuous pain spreading over the left side of the head, seeming to be concentrated in the left eye and left ear. A tender spot was found in the

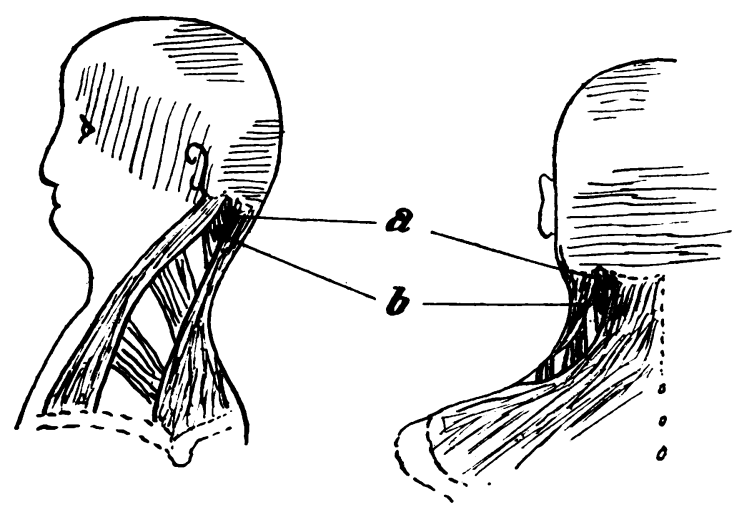

FIG. 2.-Sterno-mastoid and trapezius muscles, with clavicle. form a triangle whose floor is crossed by splenius, levator anguli scapulae and scalene muscles, in order from above downwards. $a$-Lesion in case 1 . $b$-Lesion in case 2 . Horizontal shading-Distribution of pain in case 1 . Vertical shading-Distribution of pain in case 2 . 
usual situation on the left side (Fig. 2). Injection of procaine was followed by immediate dramatic relief. Two days later he was discharged to a convalescent depot.

\section{CASE 3}

Headache following head iniury.-Sig. C.F. received a blow on the head when a military truck overturned. For two weeks afterwards he complained of a continuous headache in the right parietal region, with frequent attacks of giddiness. Radiological examination was negative. Examination revealed a well-defined area of

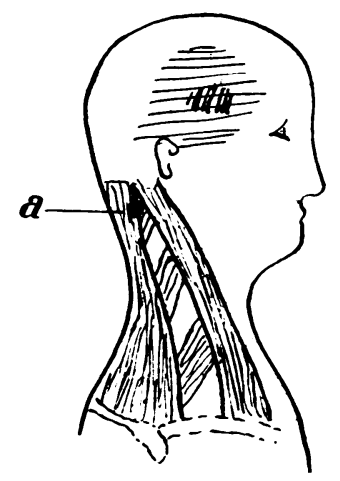

FIG. 3.- $a$-Site of lesion in case 3. Horizontal shadingdistribution of pain. Oblique shading-patch of deep hyperalgesia at temporo-parietal suture.

deep hyperalgesia, about 3 by 4 in. in the region of the right temporo-parietal suture. He was tender also in the right lateral nuchal spot. Infiltration of the latter caused a striking diminution of the deep hyperalgesia in the scalp. The relief of the headache was complete, together with the disappearance of the tenderness in both the neck and the scalp (see Fig. 3).

Comment.-The occurrence of reflex eye and ear disorders with cervical fibrositis was noted recently by Douthwaite (1942). The reflex effects of artificial deep lesions of the neck have been studied by Campbell and Parsons (1944) and by Travell (1945). Jones and Brown (1944) have reported good results with post-traumatic headaches by treating cervical lesions. Rheumatic or " indurative" headache has been known for many years, but as an uncommon rather than a common variety of headache. This is a subject which invites investigation on a large scale.

\section{THE PAINFUL SHOULDER}

Added experience has confirmed the writer in his previously expressed opinion (1942a) that the painful shoulder syndrome presents a remarkably constant clinical picture, no matter what the underlying cause. In the mildest cases the pain is felt only on abduction, while in the worst cases there is a constant severe ache, both night and day, often with profound muscular wasting and stiffness of the joint. The pain usually is felt locally over the shoulder, but it often is referred to the middle of the outer aspect of the humerus, in the region of the insertion of the tendon of the deltoid muscle. From a lesion in the supraspinous fossa pain does not commonly radiate downwards further than this; if it does so, a lesion in the forearm should be sought in addition to that in the shoulder girdle. Little or no tenderness may be observable, but, as a rule, it is possible to detect a tender spot over the greater tuberosity, in the musculo-tendinous fibres of the deltoid or in the subacromial bursa. Tenderness, even when widely spread, often can be observed to vanish completely upon the successful treatment of a myalgic lesion.

It is not intended to discuss at length the pathology of the disorder, which has been debated since the days of Duplay (1872), who described it as "periarthritis". Many writers lay the blame upon the subacromial bursa, which frequently displays crepitus on movement, and others blame the long tendon of the biceps or its sheath (Schrager, 1938; Lippmann, 1943). Calcification is found in the tendon of the supraspinatus in 5 to $10 \%$, but the significance of this would appear to diminish when it is realized that calcification occurs in $2.7 \%$ of normal shoulders (Bosworth, 1941). Codman (1934) demonstrated that the tendon of the supraspinatus was ruptured in a number of cases. This tendon, however, is remarkably subject to attrition, and to degenerative change, and partial rupture is found at autopsy in $20 \%$ of those whose deaths resulted from the common diseases of old age (Keyes, 1935). Skinner (1937) holds that each one of these phenomena may be only an incident in a progressive disturbance which involves many structures. "Thus", he says, "it is not surprising to find several aspects of the same condition described by different authors under different headings". In rather less than half of the cases the disorder results from injury, but an interval of days or weeks may elapse between the accident and the full development of the clinical picture. The fully established syndrome does not appear to vary, no matter what the exciting cause.

In the vast majority of cases it is disastrous to treat by infiltration the tender areas related to the deltoid muscle. Temporary relief is followed as a rule by a severe reaction, with worsening of the condition. The true lesion should be sought higher up, in the region of the supraspinous fossa, sometimes in the trapezius and sometimes in the supraspinatus muscle (see Cases 4, 5, and 6). A few cubic centimetres of procaine solution, correctly placed, often has been observed to abolish widespread pain and deep hyperalgesia. Less common sites for myalgic lesions are the infraspinous fossa and the paravertebral muscles near the vertebra prominens.

Of 105 cases of painful shoulder, a " supraspinous lesion" was identified in 62 . In 38 of these, immediate and lasting relief resulted from treatment.

CASE 4

Painful shoulder associated with calcification.-Sgt. Y., aged 38 , complained of pain in the left shoulder for three weeks, unrelated to injury. The pain would shoot down to the mid-humeral region on abduction and external rotation. There was no limitation of passive movement. On examination tenderness was discovered over the greater tuberosity. X-ray examination revealed a large calcified deposit in the tendon of the supraspinatus 
muscle, and a smaller one in the subscapularis tendon. There were no opaque deposits in the right shoulder. Deep tenderness was detected in or beneath the fibres of the trapezius in the mid-scapular line (the supraspinous

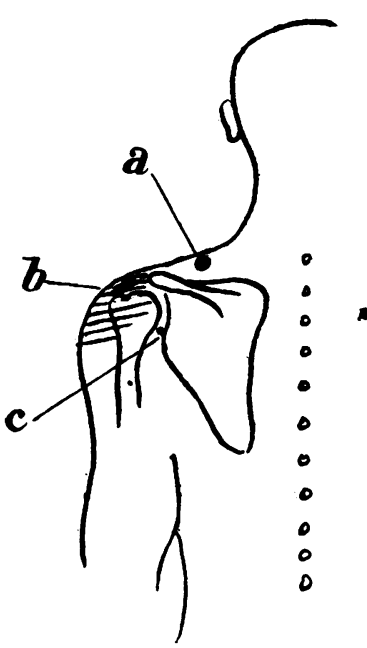

Fig. 4.

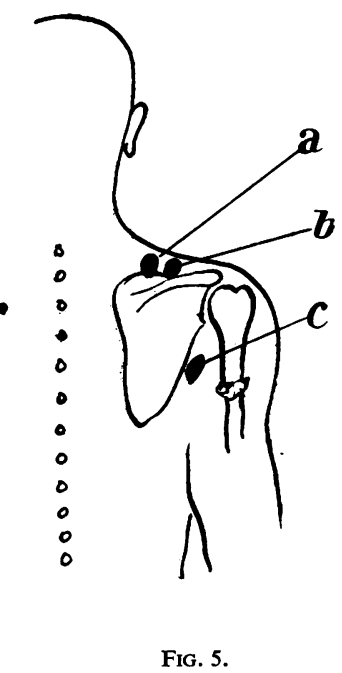

Fig. 5.
FIG. 4.-Case 4. $a$-lesion in region of supraspinous fossa. Horizontal shading-distribution of pain and tenderness. $b$ and $c$-calcification in tendons of supraspinatus and subscapularis.

FIG. 5.- $a$-Lesion in case 5. $b$-Lesion in case 6 which was responsible for limitation of abduction. $c-$ (case 6) lesion in teres major which was responsible for limitation of dorsal movement of humerus. $d$-fracture site.

spot). Infiltration of this area resulted in the abolition of the deep tenderness over the greater tuberosity, and the abatement of the pain on abduction. The pain did not recur (see Fig. 4).

\section{CASE 5}

Painful shoulder, rheumatic in origin.-E.H., aged 59, complained of a painful right shoulder, which ached at night, of six months' duration. There was no history of injury, and the $x$ ray was normal. On examination the muscles were wasted, and active abduction was limited by pain (no adhesions could be detected). Rough crepitus was observed in the subacromial bursa; and the deep tissues over the head of the humerus were tender to pressure. Tenderness was found also in the supraspinous region, and the injection of procaine abolished most of the pain on movement. Six days later there was no pain on movement, and the deep tenderness had vanished. Cure was complete and lasting, though the rough crepitus remained (see Fig. 5).

\section{CASE 6}

Painful shoulder following fracture of humerus.Pte. K.P.R., who sustained a fracture of the shaft of his right humerus on March 4, 1943, was seen at a convalescent depot on Aug. 9, 1943, the fracture having united 3 months previously. Since the accident he had complained of continuous aching in the shoulder with gross limitation of voluntary movements in all directions, more especially on abduction and on drawing the humerus directly backwards. Infiltration of a tender supraspinous spot resulted in abolition of the pain felt on abduction, though pain still was felt on dorsal flexion. A tender spot was found near the axillary border of the scapula (probably in the teres major muscle); treatment of this restored complete mobility (see Fig. 5). 18 days later he reported that the cure had been complete.

CORONARY DISEASE AND PERIARTHRITIS OF THE SHOULDER

A syndrome indistinguishable from rheumatic or traumatic periarthritis of the left shoulder occasionally accompanies coronary disease. Askey (1941) reported 22 cases in which various degrees of shoulder disability followed myocardial infarction, while Ernstene and Kinell (1940) reported 17 similar cases. In some cases the involvement of the shoulder was followed by rheumatoid changes in other joints. In the following case a picture typical of severe periarthritis followed rapidly on the occurrence of a coronary occlusion.

CASE 7

J.M., aged 60, who previously had suffered from angina of effort, collapsed with a coronary occlusion. Previously he had had a few rheumatic pains in his right shoulder, but after the coronary occlusion he suffered from continuous pain in the left side of the neck, radiating up to the occiput and out to the shoulder, with stiffness of the shoulder. The patient was short of breath, with a rapid pulse. Examination revealed a typical picture of periarthritis of the shoulder, with wasting of the deltoid and trapezius muscles, and gross limitation of abduction and external rotation of the humerus.

It has been the experience of the writer $(1942 b)$ that pain from trapezius lesions low in the neck tends to shoot both up to the occiput and out to the shoulder. This was so in the present case, and, in addition to the diffuse tenderness of the wasted muscles, two myalgic lesions were located: (1) in the edge of the trapezius at the level of C.V.7, (2) the supraspinous spot (Fig. 6). The upper lesion was injected with procaine, with the

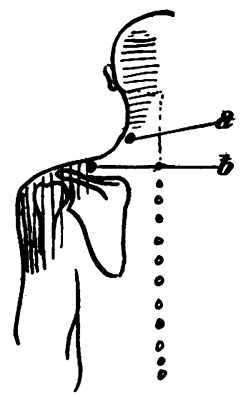

FIG. 6.-Case 7. $a$-Lesion in trapezius. $b$-supraspinous lesion. Horizontal shading-distribution of pain which was abolished on infiltration of lesion $a$. Vertical shading-painful area which remained.

result that he had no more pains in his neck and his head, though the shoulder remained stiff and painful. No further opportunity was secured of making observations, and he died six months later.

The above case is mentioned in order to illustrate the point that muscular lesions, indistinguishable from rheumatic lesions and producing muscular wasting and stiffness of joints, may result from visceral disease. Gibson (1905), who reported a case in which the syndrome was accompanied by 
hyperalgesia of the skin, regarded all the signs as reflex in origin; while Askey, too, held that the periarthritis must result from some underlying disturbance of nerves. There is, indeed, no other plausible explanation. The abnormal efferent (antidromic) impulses from the diseased viscus activate pain receptors through a wide area of somatic tissues; and the continuation of the bombardment of susceptible tissues, is (at least in part) responsible for the more obvious pathological changes which in other cases we call chronic rheumatism. Periarthritis of the shoulder of cardiac origin, therefore, provides excellent support for the reflex theory of fibrositis.

\section{PAIN IN THE FOREARM AND HAND}

Muscular pains in the forearm may be divided into two extreme types, those felt only on movement and those felt only at rest, with every stage of intervening gradation. The pain felt at rest usually is of a "neuralgic" type, associated with cramps on repeated movements. It may radiate to the tips of the digits, and often ascends nearly to the middle of the humerus. In some cases the pain may be felt only in the wrist, hand, or fingers, but the offending lesion usually is found in the upper half of the forearm. Pain is felt along the radial side or the dorsum of the forearm more commonly than along the ulnar side, and in most cases a lesion will be found immediately below the elbow at the junction of the extensor tendon with its muscle-bellies (Figs. 7 and 8). This site is tender to heavy pressure in the normal subject, but comparison with the opposite forearm usually will reveal whether or no the tenderness is greater than normal.

Pain felt only on movement often comes under the designation of "tennis-elbow". Usually the tendinous attachment to the epicondyle is tender, and injection with procaine rarely gives relief. In some cases of tennis-elbow, however, muscular lesions at the "extensor spot" have been treated with success. When such a case was cured of spontaneous pain by Kellgren (1938a), the epicondylar tenderness persisted for some weeks.

Pain of the neuralgic type often occurs in middleaged women. It usually is worst in the early hours of the morning, and it may be accompanied by swelling, numbness, tingling, and cramps in the fingers. The symptoms may be unrelated to any known cause, or they may follow an injury, either immediately or after an interval A mild infection of a finger, or a fracture of a phalanx or of the wrist, may be followed by a neuralgic pain. The offending lesion in such cases usually will not be found in the painful area, but at the common site in the upper end of the forearm. In several cases the patient was astonished at the success which accompanied the treatment of lesions whose existence he had not suspected. This phenomenon has been observed also by Good (1942), who noticed repeatedly the occurrence of myalgic spots in localized regions well removed from the damaged tissues.
CASE 8

Rheumatic pain in forearm and hand.-Mrs. P.Q., aged 41 years, for two weeks had been suffering from pains in the right shoulder and in both hands and feet. After a week the symptoms vanished from all except the right shoulder, forearm, and hand, where the pains remained severe. The shoulder presented the usual picture of periarthritis, with nocturnal aching, limitation of abduction, and tenderness over the greater tuberosity. The pain in the forearm and hand seemed to be related to a tender spot in the extensor mass two inches below the lateral epicondyle (Fig. 7). The epicondyle was tender; and a band of diffuse deep hyperalgesia, running along the radial side of the forearm, connected it with the palm of the hand, which was tender to deep pressure.

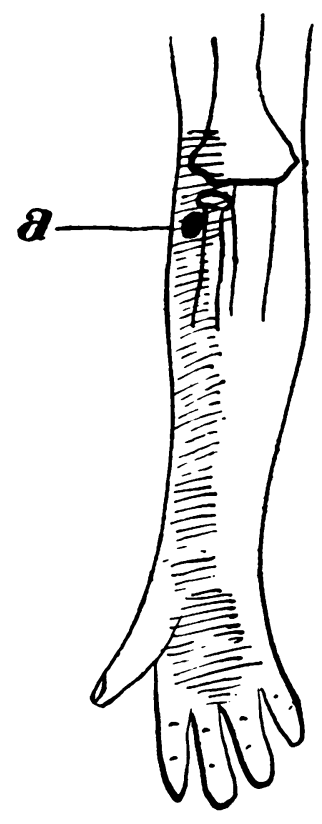

FIG. 7.

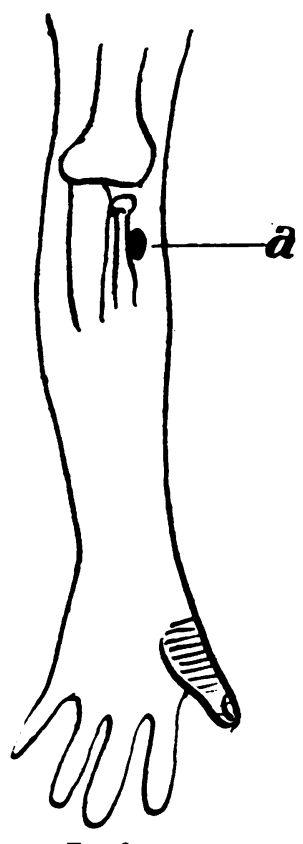

FIG. 8.
FIG. 7.- $a$-“"Extensor" lesion. Shading-deep hyperalgesia which disappeared upon infiltration of $\boldsymbol{a}$.

FIG. 8.-Cases 9 and 10. $a$-Extensor lesion which was responsib.e in each case for pain confined mainly to thumb (shaded).

There was no change in cutaneous sensibility. Injection of procaine into the extensor lesion immediately abolished all pain and tenderness in the forearm and the hand. Similar treatment to the tender area in the deltoid resulted in partial restoration of mobility to the shoulder. The pain in the forearm and hand was permanently cured, but the shoulder was much worse afterwards. This poor result in the case of the shoulder was typical of a number of cases at this stage; later study revealed that the true lesion should be sought in the region of the supraspinous fossa.

\section{CASE 9}

Pain (?rheumatic), both hands.-Mrs. R.T., aged 45, had suffered from pains and cramps in both hands for six years, with cramp on writing or gripping an object. Pains would waken her early in the mornings; the hands would swell and the fingers often were stiff. The pain was most severe in the left thumb; it seemed to shoot from the base to the tip. On examination tenderness 
was found in the left thenar eminence. The importance of the extensor lesion not having been grasped fully, injections were given into the thenar eminence, with deplorable results. For several weeks the thumb was immobilized in plaster without success. A lesion was then found in the extensor muscles in front of the neck of the left radius (Fig. 8). The result was dramatic, for she was free from pain in either hand for ten days. A second injection was given, and eight months later there had been no more pain in either hand. The right hand, she said, always would improve if the left were better.

\section{CASE 10}

Pain in thumb following a septic infection.-Mrs. L.B., aged 32, had sustained a small septic wound of the left thumb a year previously, followed by a pustular rash on both hands. The thumb never had healed; it ached at night and shooting pains were felt in it during the day. On examination the thumb was diffusely tender to deep pressure, and there was a trophic disorder of the skin of the distal third, which was thickened and fissured. The " extensor spot" was tender, and procaine solution was injected. In spite of the fact that no discomfort had been felt in the region of the elbow at any time, the pain ceased immediately, followed by healing of the thumb within a few days. Three months later the disability had not returned (Fig. 8).

\section{PLEURODYNIA}

In fibrositis of the chest wall, or pleurodynia, the pain may shoot from the back around to the front; usually it is diffuse, deep, and difficult to locate, seeming to spread through an area variable in extent. Usually the chest wall is tender, but in an occasional case tenderness is not easily demonstrable. Compression of the ribs in these cases often gives rise to diffuse sensation of pain which is not associated with discrete areas of tenderness. Careful search, however, usually reveals a small circumscribed lesion, and a correctly placed injection achieves the desired result (see Case 12). The lesion in pleurodynia usually is either traumatic or rheumatic in origin, but sometimes an exactly similar lesion follows thoracic visceral disease. Long after all physical signs have disappeared, pain persists which can be proved associated with a parietal rather than a visceral lesion (Kelly, 1944). The fact that the signs in pleurodynia do not vary, whether the original cause be rheumatic, traumatic, or visceral, suggests that the mechanism by which the syndrome is produced is the same in all three cases. But it sometimes happens that the development of a somatic lesion in association with thoracic visceral disease can be observed from the beginning. The orthodox view, which relates the pain of lung disease to irritation of the pleura, cannot be substantiated in every case. In a number of cases of pneumonia, bronchitis, or pleurisy the writer has been able to abolish the pain completely by an injection of $1 \mathrm{c.cm}$. of procaine into a localized spot in muscle. Farber (1943), Schnur (1939) and Price (1943) have had similar experiences with the so-called "pleural pain" of phthisis, pneumonia and bronchitis. Chevalier Jackson (1943) records that pain and tenderness in the chest wall frequently arise from bronchial carcinomata in which there is no involvement of the pleura. Visceral chest pain, therefore, as Sir James Mackenzie (1920) pointed out, actually arises in the muscles of the chest wall, and the change in sensibility of the chest wall is brought about by what he called a viscero-parietal reflex. When the acute lesion (the result of a viscero-parietal reflex) becomes chronic and carries over to the stage of "pleurodynia", it seems reasonable to suggest that the somatic lesion, which at first was secondary in nature, has now taken on the usual characters of a self-sufficient myalgic lesion.

This point has been laboured at length because it furnishes an interesting study of the formation of myalgic lesions as the result of known causes, in which the processes can be followed and the mechanism can be guessed at. As will appear later, the analogy is useful for a comparative study of the formation of myalgic lesions in other situations and due to other causes.

\section{CASE 11}

Thoracic pain accompanying bronchitis.-A soldier who had acute bronchitis began to suffer agonizing pain in the right chest. For 48 hours he writhed in agony with every breath or with every cough. Rhonchi were heard in both lungs, and the anterior chest wall was diffusely tender in the region of the $3 \mathrm{rd}, 4 \mathrm{th}$, and 5 th costal cartilages. A circumscribed myalgic lesion was found near the centre of this area of tenderness, in the 4th space near the costo-chondral junction (Fig. 9). $1 \mathrm{c} . \mathrm{cm}$. of procaine solution dramatically relieved all of his symptoms.

\section{CASE 12}

Pleurodynia following a cold in the chest.-Capt. Z. complained of diffuse pain in the front of the right side of the chest for a fortnight, since his recovery from a " cold." Palpation revealed diffuse tenderness between the clavicle and the 4th rib, with a localized tender area in the 3rd space just outside the costo-chondral junction. Though the space in this locality was infiltrated with $12 \mathrm{c.cm}$. of procaine solution, neither local tenderness, diffuse tenderness, nor pain on breathing was abolished. The needle point was then turned downwards behind the 4th rib; a sharp pain was felt, and the injection of $0.5 \mathrm{c} . \mathrm{cm}$. abolished permanently all signs and symptoms (Fig. 9).

\section{ABDOMINAL PAIN DUE TO SOMATIC LESIONS}

Abdominal pain, when it is the result of somatic lesions, presents many features analogous to pain in the chest wall. The pain may radiate widely from the myalgic leison, with scattered areas of secondary tenderness. Abdominal pain sometimes radiates from a myalgic lesion in the paravertebral muscles, but more commonly the lesion is situated anteriorly, near the edge of the rectus abdominis. Persistent abdominal pain often is associated with a painful operation scar; in this case the pain is more likely due to a myalgic lesion than to intra-abdominal adhesions. In a number of cases of abdominal pain, inflammatory disease of a viscus-such as 


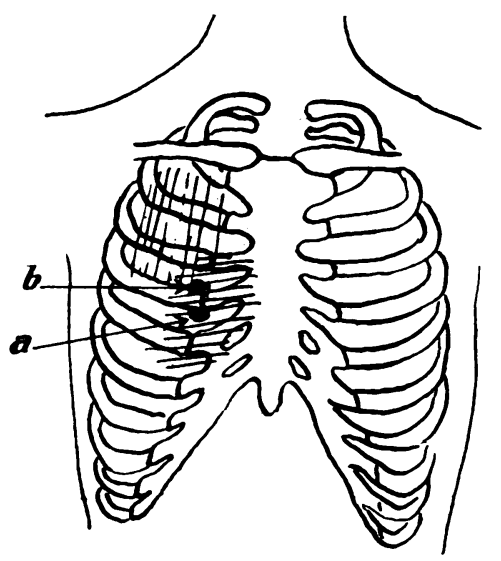

FIG. 9.- $a$-Lesion in case 11. Horizontal shading - area of tenderness which disappeared upon infiltration of lesion $a$. The pain was distributed much more widely. $b-$ Lesion in case 12 . Vertical shading -distribution of diffuse tenderness in case 12 .

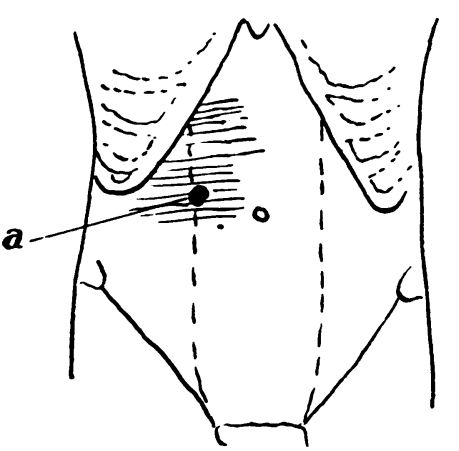

FIG. 10.-Case 13. $a$-Lesion in edge of rectus abdominis. Shading--distribution of deep tenderness.

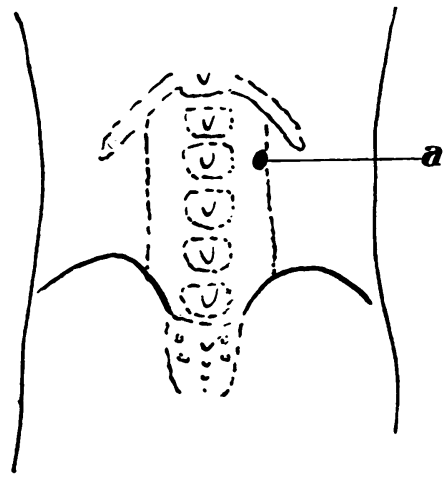

FIG. 11.-Case 14. Site of lesion in erector spinae is indicated. infectious hepatitis or bacillary dysentery-had preceded the establishment of a myalgic lesion. Pottenger (1934) has observed that abdominal pain, closely resembling the original pain, was sometimes seen to follow acute abdominal disease long after all inflammation had subsided.

Fifty-three cases have been treated successfully with local analgesia, and a large number have been investigated without success. The results corresponded generally with observations on pain in the chest and elsewhere. No matter what the original cause, whether rheumatic, traumatic, post-operative, or post-inflammatory, the fully developed syndrome showed, on the whole, a fairly constant picture.

The pain and tenderness of the abdomen which often accompanies visceral disease can be shown sometimes to depend upon myalgic lesions. Gorrell (1944) mentioned that procaine infiltration of " trigger" spots often gave striking temporary relief to the pain of malignant disease. This point is well illustrated by the following case:

\section{CASE 13}

Tender spot in the abdominal wall, associated with a carcinoma of the kidney.-A N.C.O., aged 35, was emaciated from malignant disease of the right kidney, with enlarged liver, ascites, and a secondary growth in the left thigh. He began to complain of severe pain in the right upper quadrant. The pain was diffuse and constant, although sharply accentuated by movement. Examination revealed diffuse tenderness over the right upper quadrant, with a localized area of acute tenderness in the edge of the right rectus muscle 2 inches above the level of the umbilicus. Four days after the onset of the pain, an injection of $1.5 \mathrm{c} . \mathrm{cm}$. abolished the pain on movement and diffuse tenderness, and two weeks later the pain had not recurred (see Fig. 10).

Though Case 13 cannot be presented as one of fibrositis, and the process is not a rheumatic one, the behaviour of this lesion was in every respect analogous to that of a fibrositic lesion, of whatever cause. In the case of a more chronic lesion following cured abdominal disease, the likeness to fibrositis is even closer. There is no reason, in fact, why the mechanism by which the myalgic lesion is produced should not be the same in all cases, for the end-result is the same. The study of somatic lesions of known causation, if this supposition be true, should be helpful in throwing light upon the processes by which the myalgic lesion is brought into being, and, therefore, upon the nature of rheumatism.

\section{CASE 14}

Residual backache, whose basis was a somatic lesion, remaining after an attack of renal colic.

Pte. V.P. was admitted with severe pain in the right loin, with haematuria. This was his first such attack, though five years previously the right kidney had been crushed in an accident. Investigation of the urinary tract, after the pain and haematuria had ceased, revealed no abnormality. Twelve days after admission he continued to complain of an ache in his right loin. A muscular lesion in the right erector-spinae, at the level of the second lumbar vertebra, was infiltrated. The ache immediately disappeared, only to return a week later. The same lesion was treated, with relief which this time proved lasting (Fig. 1).

McLellan and Goodell (1943), whe investigated extensively the pain reactions of the genito-urinary tract, reported three cases in which persistent muscular pains in the loin followed a day or two after a painful artificial stimulus to the ureter or kidney pelvis. In one patient, the authors say, " splinting of the ipsolateral abdominal and loin muscles, associated with pain from distention of the right ureter at $25 \mathrm{~cm}$., was also observed. There was an initial brief period of pain, scarcely outlasting the stimulus, but associated with splinting of the abdominal muscles in the right flank and loin, long outlasting the period of ureteral distention. Within an hour she began to have pain in her right 
loin. The pain was severe and persisted for two days, when it gradually diminished." Here the persistence of the "referred" pain, tenderness, and muscular spasm must have been due to a temporary change in the somatic tissues themselves.

It should not be necessary to pursue the subject into the other regions of the body, where the story is the same. The myalgic lesion may arise de novo or in association with rheumatic lesions elsewhere; it may also follow local damage to the tissues in the shape of injury or infection. No matter what the original cause, the lesion in any region tends to favour certain sites, and to be associated with diffuse pain and with secondary tenderness which follows a familiar pattern.

\section{Mechanism of the Production of a Myalgic Lesion}

When a myalgic lesion of the wall of the abdomen or chest follows visceral disease, it appears to arise through the following sequence of events: $(a)$ visceral lesion (e.g. kidney) causes reflex (" referred ") muscular spasm and deep tenderness; (b) radiation of pain impulses to "site of election in muscle" causes site to take on a degree of self-sufficiency and to form a myalgic lesion; (c) myalgic lesion displays usual secondary effects. The sequence of events would not be different when the lesion resulted from a traumatic or infective damage to nearby somatic tissues; for it has been recognized by Lewis (1942) that the mechanism which brings about referred pain and tenderness is the same whether the primary lesion be visceral or somatic. If this hypothesis be admitted, it requires only a short step to apply it to the formation of myalgic lesions in other regions, as the forearm. In Case 10 a septic infection in the thumb caused the apearance of a myalgic lesion in the upper fibres of the extensor mass. Such an observation, at first sight surprising, has been observed by the writer in so many cases that he now has little doubt of the reality of the phenomenon. Some hitherto unknown law relating to pain-spread appears to come into operation. The following case provides another example.

\section{CASE 15}

Pain in the forearm associated with a fractured finger.Pte. J.C. was kicked on the little finger at football, and on the following day he complained of pain at the site of the injury, and of a more widely-radiating pain which ascended to the elbow. Radiological examination revealed a fracture of the proximal phalanx, and further examination disclosed a sharply-localized area of deep tenderness on the dorsum of the forearm about 3 in. below the elbow (Fig. 12). Pressure on this spot caused a localized spasm of those fibres of the extensor digitorum communis which extend the little finger, bringing about involuntary extension of that digit alone. The patient was certain that there had not been any injury to the forearm. Local analgesia was not used, and the patient was not seen again.

Case 15 provides an example of the early formation of a myalgic lesion in distant tissues, in response to an injury to a digit. This is by no means a rare result of an injury to an extremity (or indeed of injury anywhere); the pain from the start is out of proportion to the injury, both in severity and extent. In a few days, as a rule, the pain disappears, but in some cases it persists and extends, giving rise to the so-called spreading post-traumatic neuralgia

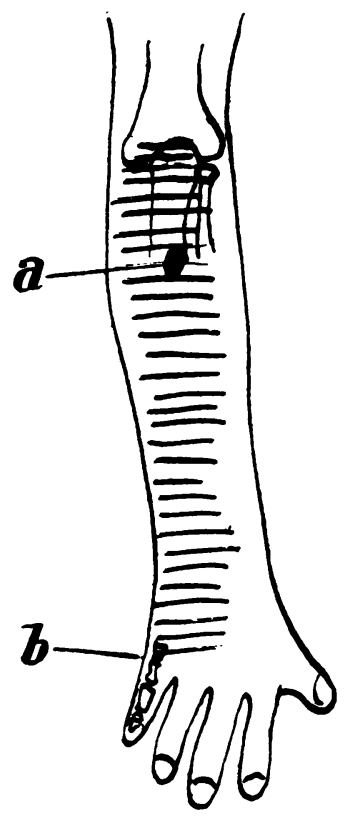

FIG. 12-Case 15. $a$-Lesion in fibres of extensor digitorum communis. $b$-Fractured proximal pha!anx or little finger. Shadirg-distribution of spontaneous pain.

(Leriche, 1939). In many of these (as in Case 10) it can be demonstrated that the pain is due to a myalgic lesion. In Case 15 we have localized tenderness, with muscular spasm localized to that part of the muscle which is functionally associated with the injured digit. A close analogy can be drawn with the case in which spasm and tenderness resulted from a painful stimulus to the kidney, and it is not unreasonable to suggest that nervous impulses played a large part in initiating the lesion. On the same analogy, it can be suggested also that the more persistent lesion in Case 10 may have been due in part to the effects of abnormal nervous impulses from the diseased thumb.

\section{Myalgic lesions of Rheumatic Origin}

The greater part of the foregoing discussion has been devoted to speculation upon the origin of lesions of strictly non-rheumatic origin. It may be objected (perhaps rightfully) that all this has little to do with fibrositis of rheumatic origin. It has been pointed out, however, that the behaviour of the fully established fibrositic syndrome differs little whether it be traumatic, infective, or rheumatic in origin; myalgic lesions in the body wall, moreover, display the same qualities even when they result from visceral disease. It is reasonable, therefore, 
to assume that, though the cause may vary, the mechanism by which the myalgic lesion is produced is the same in all cases. If this be true, it must be valid also for the formation of lesions in frankly rheumatic disease, as in cases 4, 5, 7, and 8. Many such cases, probably or certainly rheumatic in origin, could be quoted.

The object of this discussion has been to speculate upon, and if possible to discover the nature of fibrositis. The myalgic focus has been chosen as the chief lesion, which produces wide secondary effects, and its formation when secondary to nonrheumatic causes has been traced. A good deal of evidence suggests that nervous reflexes play an important part in the formation of the lesion. Where the lesion is frankly rheumatic in origin, it is reasonable to suggest again that abnormal nervous impulses must play a large part. This suggestion is supported by the observations of Gorrell (1944), Elliott (1944), and LeVay (1944) that the tender areas in the buttock and the thigh which result from a lesion of an intervertebral disc can be abolished for appreciable periods by the use of local analgesia. These myalgic lesions, obviously due to abnormal nervous impulses, behave in a fashion exactly like myalgic lesions due to other causes.

In a previous paper evidence has been produced which indicates that the essence of the fibrositic syndrome consists of the myalgic lesion with its reflex effects. In this paper it has been suggested that the myalgic lesion itself results largely from reflex nervous influences. The wider application of the theory to rheumatic pain in general will be reserved for a later essay.

\section{Summary}

1. Myalgic lesions show an unaccountable predilection for certain specified sites in the somatic tissues.

2. Lesions not strictly rheumatic in origin, such as those which follow injury or infection of tissues, tend to obey the same general law.
3. Painful lesions of the body wall, which accompany or follow disease of the viscera, behave like myalgic lesions both in their distribution and in their response to local analgesia.

4. An analysis of the mechanism by which such lesions arise indicates that viscero-parietal nervous reflexes play an important part in their production.

5. By similar analysis, and by analogy, it is suggested that abnormal nervous impulses play an important part in the production of post-traumatic and post-infective myalgic lesions in other parts of the body and limbs.

6. Extending the analogy to rheumatic lesions, it is suggested that nervous reflexes are instrumental in the causation of fibrositic lesions in general.

7. The reflex theory of the causation of the myalgic lesion is complementary to an earlier hypothesis, which suggested that the widespread effects of the lesion itself are reflex in origin.

\section{REFERENCES}

Askey, J. M. (1941). Amer. Heart J., 22, 1.

Bosworth, B. M. (1941). J. Amer. med. Ass., 116, 2477.

Campbell, D. G., and Parsons, C. M. (1944). J. nerv. ment. Dis., 99, 544.

Codman, E. A. (1934). “The Shoulder." Boston.

Douthwaite, A. H. (1942). Medical Annual, p. 271. Bristol.

Duplay, S. (1872). Arch Gén. Méd., 2, 513.

Elliott, F. A. (1944) Lancet, 1, 47.

Ernstene, A. C., and Kinell, J. (1940). Arch. intern. Med., 66, 800.

Farber, J. E. (1943). Amer. Rev. Tuberc., 47, 469.

Gibson, G. A. (1905). Brain, 28, 52.

Good, M. (1942). Practitioner, 148, 236.

Gorrell, R. L. (1944). Amer. J. Surg., 63, 102.

Jackson, Chevalier (1943). Proc. Ass. Res. nerv. ment. Dis., 23, 271. Jones, O. W., and Brown, H. A. (1944). J. nerv. ment. Dis., 99, 668. Kellgren, J. H. (1938). Brit. med. J., 1, 325.

Kelly, M. (1942a). Med. J. Austral., 1, 488.

- (1942b). Ibid., 2, 479.

(1944). Ibid., 1, 4 .

(1945). Annals of the Rheumatic Diseases, 5, 1

Keyes, E. L. (1935). J. Bone Jt. Surg., 17, 953.

Leriche, R. (1939). "The Surgery of Pain." London.

LeVay, A. D. (1944). Lancet, $1,116$.

LeVay, A. D. (1944). Lancet, 1, 116.

Lewis, T. (1942). "Pain." Arch. Surg., 47, 283.

Lippmann, R. K. (1943). "Arch. Surg., 47, 283. London.

McLellan, A. M., and Goodell, H. (1943). Proc. Ass. Res. nerv. ment. Dis., 23, 252.

Pottenger, F. M. (1934). J. Amer. med. Ass., 102, 341.

Price, H. J. (1943). Ibid., 123, 628.

Schnur, S. (1939). Ann. intern. Med., 13, 845.

Schrager, V. L. (1938). Surg. Gynec. Obstet., 66, 785.

Skinner, H. A. (1937). J. Bone Jt. Surg., 19, 137.

Travell, J. (1945). Personal Communication. 